\title{
Experimental Investigation and Optimization of Flatness and Surface Roughness using Grey Relational Analysis for WCB Material during Face Milling Operation
}

\author{
S. Sheth ${ }^{1 *}$, P. George ${ }^{2}$ \\ ${ }^{1}$ Associate Professor, G.H. Patel College of Engineering \& Tech, VV Nagar, Gujarat, India \\ ${ }^{2}$ Professor, B V M Engineering College, VV Nagar, Gujarat, \\ \{shethsaurin81@gmail.com\}
}

\begin{abstract}
The right selection of the machining process parameters may help to achieve the desired dimensional and geometric tolerances, to meet the functional requirements. In the present study to know the effect of machining parameters, during face milling operation, on surface roughness and flatness various experiments are performed by varying spindle speed, feed rate and depth of cut. The work piece material is Wrought Cast Steel grade B (WCB), as it widely used in manufacturing of valves due to its less cost. Experiments are performed using $2^{3}$ full factorial designs with four centre points. The values of flatness and surface roughness are critical in the case of dual plate check valve, as it affects a lot during leakage testing. To achieve the desire value of flatness and surface roughness simultaneously machining parameters need to be controlled; hence the research is carried out and Grey Relational Analysis (GRA) of the data is carried out. The flatness and surface roughness is measured using CNC Coordinate Measuring Machine (CMM) and surface roughness tester respectively. The GRA gives the second run order as the optimized one. The second run order is having spindle speed of 1200 $\mathrm{rpm}$, feed rate of $150 \mathrm{~mm} / \mathrm{min}$ and dept of cut $0.1 \mathrm{~mm}$. This run order gives the optimum value of surface roughness is $2.1035 \mu \mathrm{m}$ and flatness is $0.019 \mathrm{~mm}$.
\end{abstract}

Keywords: Face Milling, Flatness, Surface Roughness, GRA, CNC CMM

\section{Introduction}

The rise in the productivity and trust for quality is the need of every industry. Machining is the most widely used in mechanical manufacturing processes. Among various conventional machining processes, milling is used as one of the most widely used metal removal processes in industries due to its capability of rapid material removal rate. The produced milled surfaces are largely used to mate with other parts. The quality of finished products is defined by how closely the finished product adheres to certain specifications, including dimensions and surface quality [2]. In the current scenario even geometrical and form tolerances are also impacting on the quality of finished parts during assembly. Due to globalization various parts are manufactured at different locations, so for uniform interpretation of drawings and cost effective assembly one has to put proper geometrical tolerances. By using GD\&T, one can ensure the proper assembly of mating parts which improves quality and reduces the rework. [1]. In the present study the case of dual plate check valve, made of WCB material, is considered for research. The face milling operation is performed to achieve the desired functional requirements and for proper assembly purposes.

Kovac et al have studied face milling operation and a predicative model of surface roughness is developed using regression and fuzzy logic. He has included the tool wear as parameter and its influence on the surface roughness was noticed [2]. D. Baijic et al studied the effect of speed, feed and depth of cut on the surface roughness during face milling. Regression analysis and neural networks had been applied on the experimentally determined data to predict surface roughness [3-4]. Sheth et al have analysed flashing process for better MRR and spread during manufacturing of precision steel ball, as here along with the MRR the geometry of ball is also important for better functioning of ball bearing [13-15].

B. Iyer, S. Nalbalwar and R. Pawade (Eds.)

ICCASP/ICMMD-2016. Advances in Intelligent Systems Research.

Vol. 137, Pp. 65-70.

(C) 2017. The authors - Published by Atlantis Press

This is an open access article under the CC BY-NC license (http://creativecommons.org/licens)es/by-nc/4.0/).

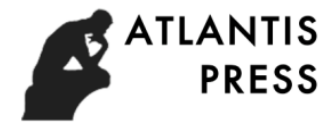


The model of dual plate check valve is shown in Fig. 1. The face milling operation is to be performed on the hard faced surfaces, which is obtained through MIG welding [5-6]. From the figure it can be seen that the two matting surfaces together create metal to metal seal for reduction in leakage. Flatness and surface roughnessplay a vital role in achieving these metal to metal seal. Now the value of flatness as geometric tolerance is highly process dependent. The Flatness values may be measured using dial indicator, CMM or by other indirect methods [7-9]. Thus the selection of machining parameters for this process becomes a vital requirement for reduction of rework, leakage and to increase the productivity in the case of dual plate check valve. Thus this investigation may help a lot to the practising engineers working with the similar kind of problem.
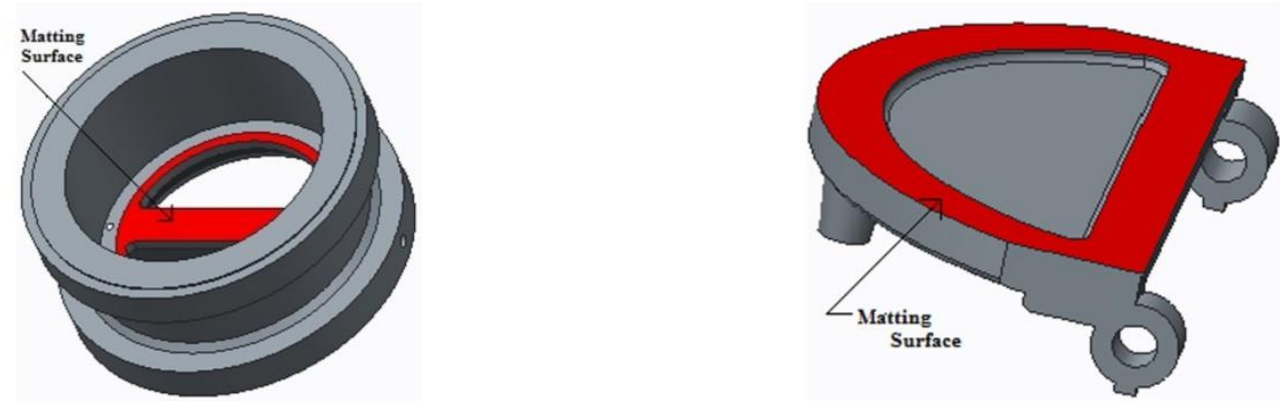

Fig. 1. Conceptual model of valve body and door [5-7]

\section{Experimental Work}

\subsection{Material, Machining and Experimentation}

The test specimen material is WCB; having size of $60 \mathrm{~mm}$ x $60 \mathrm{~mm}$ x $50 \mathrm{~mm}$. Majority of the valve manufacturers uses this material due to its less cost [5-6]. Experiments by varying speed, feed and depth of cut were performed on $\mathrm{CNC}$ milling machine. $2^{\wedge} 3$ full factorial design with four center points is selected. The experiments are performed at various levels which can be seen in Table 1. Here Miracle coated VP15TF insert is used. Fig. 2 shows the face milling operation performed by clamping the block using hydraulic vice [11-12].

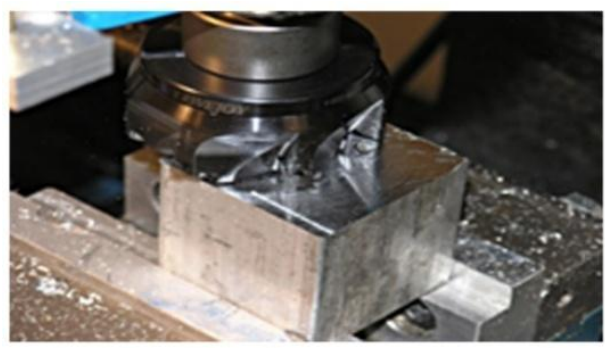

Fig. 2. Machining of work-piece [11]

Table 1 Factors and Levels

\begin{tabular}{|c|c|c|c|c|}
\hline Factors & Coded Factors & Low level (-) & High level (+) & Center points \\
\hline Spindle speed (rpm) & A & 500 & 1200 & 850 \\
\hline Feed (mm/min.) & B & 150 & 300 & 225 \\
\hline Depth of cut (mm) & C & 0.1 & 0.5 & 0.3 \\
\hline
\end{tabular}

\subsection{Measurement of flatness and surface roughness}

Hexagon make CNC CMM, with temperature compensation, is used for flatness measurement as shown if Fig 3 (a). The rectangular grid strategy for point selection is adopted and points are extracted from the surfaces having $35 \mathrm{~mm}$ x $35 \mathrm{~mm}$ cross section with $5 \mathrm{~mm}$ grid size. Surf test SV-2100 as shown in fig. 3 (b) is used for surface roughness measurement [11-12]. overcut, whereas "higher-the better" quality characteristic for MRR. 


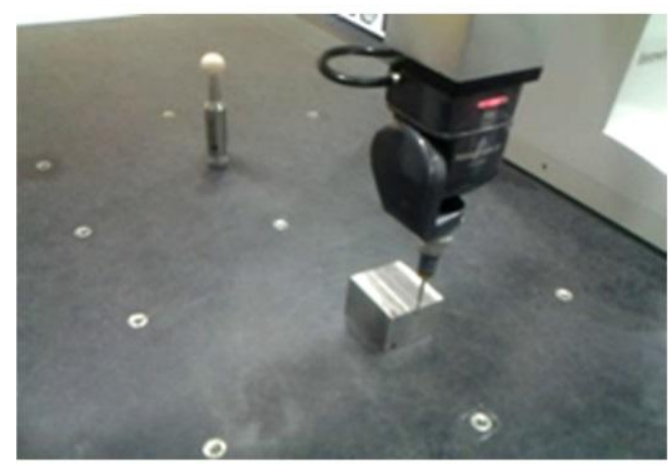

Fig. 3. (a) Flatness measurement on CMM [12]

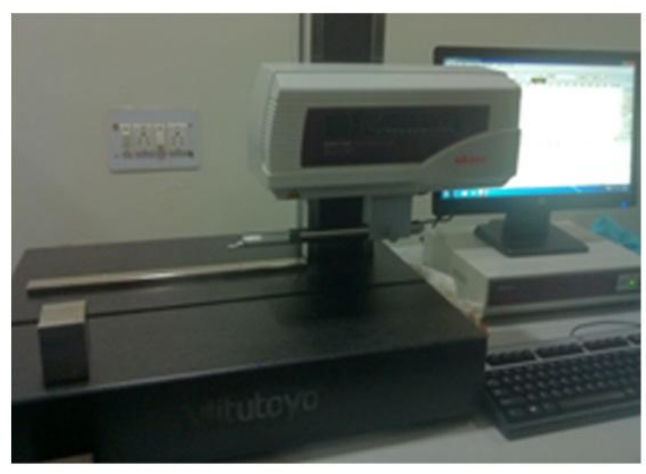

Fig. 3. (b) Surface Roughness Measurement [12]

\section{Results and Discussion}

The flatness and surface roughness values as per coded factors and treatment combinations are tabulated in Table 2 [10-12]. From the Fuzzy surfaces and main effect plots, it can be seen that flatness error will be minimum at high spindle speed, medium feed rate and at lower depth of cut. While the best surface roughness can be achieved at higher spindle speed, lower feed rate and high depth of cut [11-12]. The controversy in feed rate and depth of cut suggests multi objective optimization. So, Grey Relational Analysis (GRA) is used to optimize the process parameters to get the desire responses in multi objective optimization [16].

\subsection{Grey Relational Analysis}

Step 1: Normalize the data.

The first step of grey relational analysis is to normalize the experimental data (in the range between 0 to 1 ). In the present study the objective is to minimize the surface roughness and flatness, so "lower is better" characteristics of grey relational was used to normalize the data. For this the Eq. (1) is used [16]. The normalize values are tabulated in Table 3.

$$
X_{i}^{*}(k)=\frac{\max X_{i}^{0}(k)-X_{i}^{0}(k)}{\max X_{i}^{0}(k)-\min X_{i}^{0}(k)}
$$

Table 2 Result of surface roughness and flatness for various treatment combinations

\begin{tabular}{|c|c|c|c|c|c|}
\hline \multirow{2}{*}{$\begin{array}{c}\text { Treatment } \\
\text { Combination }\end{array}$} & \multicolumn{3}{|c|}{ Coded Factors } & \multicolumn{2}{c|}{ Responses } \\
\cline { 2 - 6 } & $\mathrm{A}$ & $\mathrm{B}$ & $\mathrm{C}$ & Flatness $(\mathrm{mm})$ & Surface roughness $(\mu \mathrm{m})$ \\
\hline $\mathbf{1}$ & - & - & - & 0.027 & 2.1195 \\
\hline $\mathbf{a}$ & + & - & - & 0.019 & 2.1035 \\
\hline $\mathbf{b}$ & - & + & - & 0.038 & 5.7466 \\
\hline $\mathbf{a b}$ & + & + & - & 0.028 & 4.4532 \\
\hline $\mathbf{c}$ & - & - & + & 0.026 & 2.5713 \\
\hline ac & + & - & + & 0.023 & 6.7697 \\
\hline bc & - & + & + & 0.040 & 2.0633 \\
\hline abc & + & + & + & 0.028 & 2.8351 \\
\hline \multirow{3}{*}{ Center Points } & 0 & 0 & 0 & 0.021 & 2.8004 \\
\cline { 2 - 6 } & 0 & 0 & 0 & 0.018 & 3.0775 \\
\cline { 2 - 6 } & 0 & 0 & 0 & 0.020 & 2.4305 \\
\cline { 2 - 6 } & 0 & 0 & 0 & 0.018 & \\
\hline
\end{tabular}

Step 2: Calculating the Grey Relational Co-efficient \&Grey Relational Grade

Grey relational co efficient denotes the relationship between the ideal and the actual experimental results. It can be calculated by Eq. (2). 


$$
\varsigma_{i}(k) \frac{\Delta_{\min }+\varsigma \Delta_{\max }}{\Delta_{o i}(k)+\varsigma \Delta_{\max }}
$$

Here $\xi$ is distinguishing coefficient and is used to adjust the difference of relational co efficient: $\xi \in[0,1] . \xi=0.5$ is considered for the present analysis. The grey relational coefficients are shown in Table 3. With the help of Eq. (3) the grey relational grades are calculated [16]. The grey relational coefficients and grades are shown in Table 3.

$$
\gamma_{i}=\frac{1}{n} \sum_{k=1}^{n} \varsigma_{i}(k)
$$

Higher grade relational grade indicates that the experimental value to the ideal normalized values is closer. Thus, higher grey relational grade means that the corresponding parameter combination is closer to the optimal. As per Fig. 4 the run order 2 is having highest grey relational grade. It means 2 nd run order gives the proper set of the cutting parameters for the optimum surface roughness and flatness.

\begin{tabular}{|c|c|c|c|c|c|}
\hline \multirow[b]{2}{*}{ Run Order } & \multicolumn{2}{|c|}{ Normalized Values } & \multicolumn{2}{|c|}{ Grey relational coefficients } & \multirow[b]{2}{*}{$\begin{array}{l}\text { Grey relational } \\
\text { grade }\end{array}$} \\
\hline & $\begin{array}{l}\text { Surface roughness } \\
\text { smaller the better }\end{array}$ & $\begin{array}{c}\text { Flatness smaller } \\
\text { the better }\end{array}$ & $\begin{array}{c}\text { Surface } \\
\text { Roughness }\end{array}$ & Flatness & \\
\hline 1 & 0.926295828 & 0.5909 & 0.871529 & 0.55 & 0.710765 \\
\hline 2 & 0.929667088 & 0.9545 & 0.876681 & 0.916667 & 0.896674 \\
\hline 3 & 0.162052255 & 0.0909 & 0.373707 & 0.354839 & 0.364273 \\
\hline 4 & 0.434576485 & 0.5455 & 0.469297 & 0.52381 & 0.496553 \\
\hline 5 & 0.831099874 & 0.6364 & 0.747496 & 0.578947 & 0.663222 \\
\hline 6 & 1 & 0.7727 & 1 & 0.6875 & 0.84375 \\
\hline 7 & 0 & 0.0000 & 0.333333 & 0.333333 & 0.333333 \\
\hline 8 & 0.938137379 & 0.5455 & 0.889897 & 0.52381 & 0.706853 \\
\hline 9 & 0.775516224 & 0.8636 & 0.690147 & 0.785714 & 0.73793 \\
\hline 10 & 0.782827644 & 1.0000 & 0.697182 & 1 & 0.848591 \\
\hline 11 & 0.724441635 & 0.9091 & 0.644697 & 0.846154 & 0.745425 \\
\hline 12 & 0.860766962 & 1.0000 & 0.782187 & 1 & 0.891094 \\
\hline
\end{tabular}

Table 3 Values Associated with Grey Relational Analysis

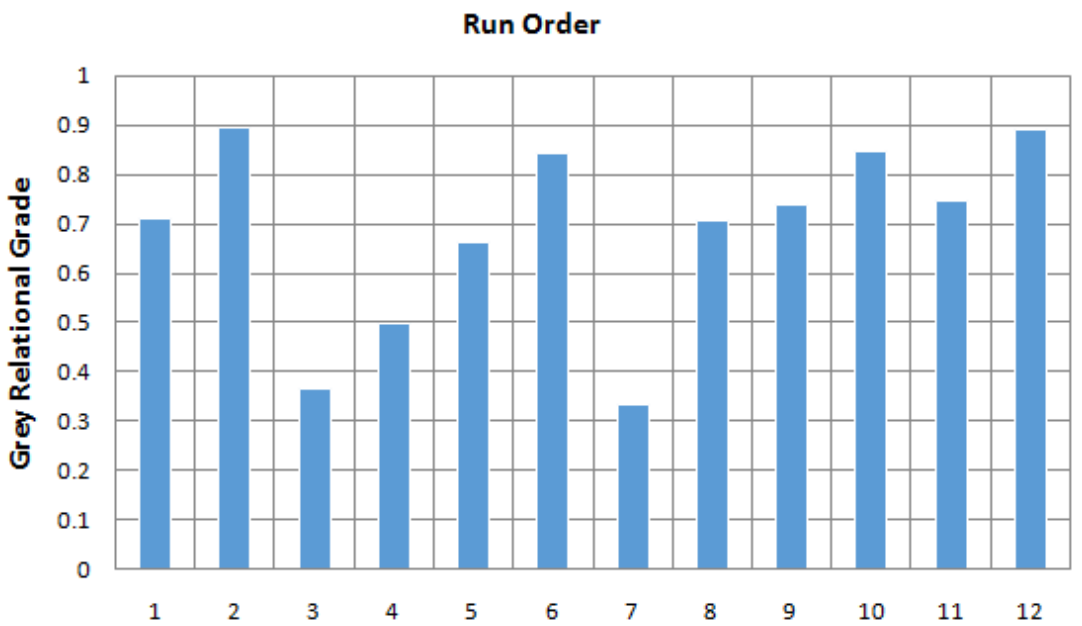

Fig. 4. Run order vs. grey relational grade 


\section{Conclusions and Future Scope}

The present paper describes the case of dual plate check valve manufacturing, to be specific face milling operation is studied and analyzed. Here the flatness and surface roughness, the response variables, are modeled in the context of machining parameters spindle speed; feed rate and depth of cut, to know its impact on quality of machined surfaces. From the Fig. 2 it seems that the largest grey relation grade is attained for second run order. At this run order the values of machining process parameters are spindle speed of $1200 \mathrm{rpm}$, feed rate of 150 $\mathrm{mm} / \mathrm{min}$ and depth of cut of $0.1 \mathrm{~mm}$. So, this set of combination optimizes flatness error and surface roughness, which are $0.019 \mathrm{~mm}$ and $2.1035 \mu \mathrm{m}$ respectively. As face milling is crucial operation before grinding, so even this analysis may reduce the number of grinding passes. Later on same analysis may be extended for grinding operation. Other valve materials like CF8M, CF3M, Inconel and Aluminium Bronze may also be selected as work piece material for future analysis.

\section{Acknowledgement}

The authors thank to Mr. Paresh Thakar of Flovel valves Pvt Ltd., GIDC, VU Nagar, Gujarat, India for their support in providing \& discussing the industrial problem. Even the authors would be grateful to Er. Vivek Thakar of Flovel valves, as his constant support and encouragement helps a lot in conducting the experiments.

\section{References}

[1]. P. J. Drake, Dimensioning and Tolerancing Handbook, McGraw-Hill, 2009.

[2]. P. Kovac, D. Rodic, V. Pucovsky, B. Savkovic, M. Gostimirovic, "Application of fuzzy logic and regression analysis for modeling surface roughness in face milling”, Journal of intelligent manufacturing, 24 (2013), 755-762.

[3]. B. Lela, D. Bajic, S. Jozic, "Regression analysis, support vector machines, and Bayesian neural network approaches to modeling surface roughness in face milling", International Journal of Advanced Manufacturing Technology, 42 (2009), 1082-1088.

[4]. D. Bajic, B. Lela, D. Zivkovic, "Modeling of machined surface roughness and optimization of cutting parameters in face milling", Metalurgija, 47 (2008) 4, 331-334.

[5]. T. Patel, S. Sheth, B.S. Modi, P. Patel, "Experimental investigation and Forecast of Weld penetration in MIG Welding Process on WCB Material", Proceeding of the international conference on Advances in Production and industrial Engineering, 2015, 186-191. DOI: 10.13140/RG.2.1.3550.4163.

[6]. S. Sheth, B.S. Modi, T. Patel, P. M. George, "A Fuzzy Logic Based Model to Predict Weld Width-A Case Study of Hard Facing Process Using MIG Welding on Dual Plate Check Valve", Applied Mechanics and Materials, 592-594 (2014), 8-12. DOI: 10.4028/www.scientific.net/AMM.592-594.8

[7]. S. P. Frechette, A. T. Jones, B. R. Fischer, "Strategy for testing conformance to geometric dimensioning \& tolerancing standards", Procedia CIRP, 10 (2014), 211-215.

[8]. B. Mistry, P. M George, S. Sheth, "Study and scope of DFMA and GD\&T in manufacturing process: A case study on dual plate check valve", Proceeding of 7th International Conference on Advanced Computing and Communication Technologies(ICACCT TM-2013),2013,DOI: 10.13140/2.1.2294.8642.

[9]. B. S. Modi, P. M. George, S. Sheth, "Study and investigate effect of cutting parameters on flatness for dual plate check valve", Proceeding of 7th International Conference on Advanced Computing and Communication Technologies (ICACCT TM-2013), 2013, DOI: 10.13140/2.1.3867.7286

[10]. D. C. Montgomery, Design and Analysis of Experiments, John Wiley \& Sons, 7th Edition, 2009.

[11]. S. Sheth, P. M. George, "Experimental Investigation and Fuzzy Modelling of Flatness and Surface Roughness for WCB Material Using Face Milling Operation", In CAD/CAM, Robotics and Factories of the Future, 2016, 769-777, Springer India, DOI: 10.1007/978-81-322-2740-3_74

[12]. S. Sheth, P. M. George, "Experimental Investigation and Prediction of Flatness and Surface Roughness during Face Milling Operation of WCB Material”, Procedia Technology, 23 (2016), 344-351. 
[13]. P. J. Patel, S. Sheth, "Effect of Various Parameters on Material Removal Rate in Flashing Operation of Precision Steel Ball Manufacturing Process", 1st International and 16th National Conference on Machines and Mechanisms (iNaCoMM2013), 2013, 332-338.

[14]. P. J. Patel, S. Sheth. P. Chauhan, "Effect of Various Parameters on Spread in Flashing Operation of Precision Steel Ball Manufacturing Process", Procedia Materials Science, 5 (2014), 2224-2232.

[15]. S. Sheth, B. S. Modi, P. M. George, P. Patel, “A Fuzzy Logic based Model to Predict MRR in Flashing Operation of Precision Steel Ball Manufacturing Process”, Procedia Materials Science, 5 (2014), 18371845.

[16]. S. Sheth, P. M. George, "Experimental Investigation, Prediction and Optimization of Cylindricity and Perpendicularity during Drilling of WCB Material Using Grey Relational Analysis", Precision Engineering, 45 (2016), 33-43. http://dx.doi.org/10.1016/j.precisioneng.2016.01.002 